\title{
Transformaciones de los primeros escenarios sexuales de los varones
}

\author{
Transformations of the early sexual stages of young man
}

\author{
Antonio López-Castedo, José Luís Diéguez, Encarnación Sueiro \\ Facultad de. Ciencias de la Educación, Universidad de Vigo - Campus de Ourense
}

\begin{abstract}
Resumen
Estudiamos los cambios en las primeras conductas coitales, en los hombres, durante un intervalo de 10 años. Para ello se llevó a cabo un estudio longitudinal, diacrónico o transversal y de tendencia sobre una muestra de 2245 (curso 97-98) y 856 (0708) universitarios, de primer y último curso en la Universidad de Vigo. Se les aplicó una encuesta estructurada, anónima y voluntaria en la que se recogía la edad y variables sexuales, referidas a las primeras conductas coitales. Los datos se analizan mediante el SPSS 21.0. Las edades medias son de 20,85 (97-98 y de 21,42 (07-08). Hay diferencias significativas $(\mathrm{p}<.05)$ entre ambos grupos en cuanto al inicio coital (frecuencia y edad), pvinculación con pareja de primer coito, satisfacción, motivación, lugar, frecuencia, número de paraejas, orgasmo, consumo de alcohol, uso de anticoncepción y su propuesta.
\end{abstract}

Palabras clave: coito, universitarios

\begin{abstract}
In the last decades, sexuality is one of the facets that raises more interest among evolutionary researchers. In this research the change occurred in the noncoital behavior that are analyzed in males, for a period of 10 years. It took a very lengthy study, diachronic o transversal, with a trend over a sample of 2245 young university students (course 97-98) and 856 (course 07-08), in they were in their first and last year of their university course, in the University of Vigo. It was applied a structured survey, anonymous and voluntary, in which was the ages and variables were gathered, contemplating their noncoital behavior. The average age of university male, course 97-98, was of the ages 20-85 years old and the course 0708 , was of the ages 21-42 years old. The data was anaylzed using the statistical program SPSS 21.0. Keywords: coital, universitary male]
\end{abstract}

\section{Objetivo}

Conocer las transformaciones acaecidas en los últimos escenarios sexuales.

\section{Método}

Estudio longitudinal, diacrónico o transversal y de tendencia, con una muestra de 2245 (curso 97-98) y 856 (07-08) universitarios, de primer y último curso en la Universidad de Vigo, en el Campus de Vigo, de Ourense y de Pontevedra, de la Universidad de Vigo, en el curso 2007-2008.

A toda se le aplicó una encuesta estructurada, anónima y voluntaria en la que se recogía la edad y variables referidas al primer coito: su inicio y edad de comienzo, sexo de la primera pareja, tipo de pareja, sentimientos en ese primer encuentro, tiempo de conocimiento previo, razones que la motivaron, lugar en el que aconteció, frecuencia y número de parejas durante el primer año, existencia de orgasmo, consumo etílico, uso de protección, tipo, existencia de problemas con su uso y quien la propone.

Los datos se analizan mediante el programa estadístico SPSS 17.0. para hallar la Media y Desviación Típica (S), para la descripción de las variables cuantitativas, y la frecuencia y porcentaje, para la descripción de las variables cualitativas. Para hallar las diferencias significativas, empleamos la prueba t, y la Chi cuadrado.

\section{Resultados}

La edad media de los hombres universitarias, del curso 97-98, es de 20.85 años (D.T.: 2.54) y la de las del curso 07-08, es de 21.42 años (D.T.: 2.91).

El 50.6\%, de los hombres del curso 97-98 habían iniciado sus coitos, a una edad media de 18.00 años, lo mismo que el $78.3 \%$ de las del curso 07-08, a una edad media de 16.97 años. Entre ambos grupos, se han encontrado diferencias significativas en cuanto al porcentaje de comienzo $\left(\chi^{2}=193.26 ; \mathrm{p}=0.000\right)$ y a la edad de inicio $(\mathrm{t}=18.616 ; \mathrm{p}=0.000)$.

Los resultados que siguen sólo se refieren a las hombres que afirmaron haber iniciado las relaciones coitales

El 90.2\% del cuso 97-98 y el 91.9\% del 07-08 iniciaron su primera experiencia coital con una persona de diferente sexo; sin embargo, un $9.0 \%$ de los primeros y un $7.2 \%$ de los segundos, lo iniciaron con personas del mismo sexo, no encontrando diferencias significativas entre ambos grupos de hombres $\left(\chi^{2}=2.92 ; p=0.231\right)$.

El $60.8 \%$ de los varones de la primera muestra y el $53.7 \%$ de la segunda, afirmaron que su primer coito fue con su novia; mientras que un $28.6 \%$ y un $33.0 \%$, respectivamente, lo realizaron con una amiga; un $4.9 \%$ y un $2.7 \%$, respectivamente, con una prostituta, y para un $4.5 \%$ y un $9.4 \%$, respectivamente, con otras personas, existiendo diferencias significativas en función del curso $\left(\chi^{2}=28.80 ; p=0.000\right)$.

El $62.3 \%$ de los chicos, del curso $97-98$, y el $74.0 \%$, del curso 07-08, declaran que se sintieron satisfechos en ese primer coito; sin embargo, un $28.1 \%$ de la primera muestra y un $21.9 \%$ de la segunda, se sintieron 
indiferentes, insatisfechos, mal o preocupados, encontrando diferencias significativas entre ambos grupos $\left(\chi^{2}=45.85 ; \mathrm{p}=0.000\right)$.

El $40.8 \%$ de los hombres del curso $97-98$, y el $43.3 \%$ de del curso 07-08, manifestaron que hacía más de 1 mes pero menos de 1 año que conocía a su primera pareja coital; 1 año o más para un $33.6 \%$ de los primeros y un $31.2 \%$ de los segundos y de menos de 1 mes para un $25 \%$ de ambas muestras, no hallándose diferencias significativas entre los dos grupos $\left(\chi^{2}=2.43 ; p=0.657\right)$.

El $74.0 \%$ de la primera muestra y el $71.0 \%$ de la segunda tuvieron su primer coito porque sentían deseo, por estar enamorado (32.5\% y $27.0 \%$, respectivamente) y curiosidad $(22.5 \%$ y $19.9 \%$, respectivamente); sin embargo, en los restantes motivos (temor a perder a mi pareja, presionada por mi pareja, presionado por mi grupo de amistades y deseaba tener un hijo) se presentan porcentajes minoritarios, encontrándose diferencias significativas entre ambos grupos en cuanto a estar enamorado $\left(\chi^{2}=5.84 ; \mathrm{p}=0.016\right)$ y temor a perder a la pareja $\left(\chi^{2}=8.47 ; \mathrm{p}=0.004\right)$ y no en sentír deseo $\left(\chi^{2}=\right.$ $2.04 ; \mathrm{p}=0.153)$, curiosidad $\left(\chi^{2}=1.85 ; \mathrm{p}=0.173\right)$, presionada por mi pareja $\left(\chi^{2}=1.29 ; \mathrm{p}=0.256\right)$, presionada-o por mi grupo de amistades $\left(\chi^{2}=0.22 ; \mathrm{p}=\right.$ $0.632)$ y deseaba tener un hijo-a $\left(\chi^{2}=0.24 ; \mathrm{p}=0.622\right)$.

La primera relación coital ocurre en casa propia y prestada (33.8\% y $16.8 \%$, respectivamente), para quienes cursaban en $97-98$ y para los del $07-08$, el $38.2 \%$ (casa propia) y $23.1 \%$ (casa prestada). A su vez, un $12.8 \%$ de los primeros y un $8.1 \%$ de los segundos, la realizaron en el coche; un $11.3 \%$ y un $8.7 \%$, respectivamente, en Hotel/Motel/Pensión, y para un $16 \%$, de cada una de las muestras, en un espacio público. Hay diferencias significativas $\left(\chi^{2}=28.63 ; p=0.000\right)$ entre ambas muestras de varones.

El $26.8 \%$ de los hombres, del curso $97-98$, y el $28.7 \%$, del curso 07-08, tuvieron una frecuencia coital en el primer año de 1 a 3 veces/mes. Porcentajes similares se encuentran en las frecuencias de menos de una vez al mes y de 1 a 3 veces/semana. Un $17.0 \%$ de los varones de la primera muestra y un $12.4 \%$ de la segunda, solo realizaron el coito la primera vez; sin embargo, un $8.0 \%$ de los primeros y un $11.2 \%$ de los segundos, lo realizaron con una frecuencia de 4 o más veces a la semana, observándose diferencias significativas entre ambos grupos de hombres $\left(\chi^{2}=13.456 ; p=0.019\right)$.

El $64.8 \%$ y $59 \%$ de de los hombres, del curso $97-98$ y 07-08, respectivamente, tuvieron una única pareja sexual en el primer año; un $16.7 \%$ de los primeros y un $20.0 \%$ de los segundos, tuvieron dos y un $15.3 \%$ y un $18.1 \%$, respectivamente, tres o más, encontrando diferencias significativas $\left(\chi^{2}=14.503 ; \mathrm{p}=0.006\right)$ entre ambos grupos.

El $82.8 \%$, del curso $97-98$ y el $81.5 \%$ del curso $07-08$ sintieron orgasmo en su primer coito; sin embargo, un $15.0 \%$ de los primeros y un $17.0 \%$ de los segundos, no, no hallando diferencias significativas entre ambas muestras $\left(\chi^{2}=1.19 ; \mathrm{p}=0.274\right)$.

El $69.3 \%$ de los chicos, del curso 97-98, y el 63.6\%, del curso 07-08, no consumieron alcohol en el primer coito; sin embargo, un $29.5 \%$ de los primeros y un $34.8 \%$ de los segundos sí lo consumieron. Hay diferencias significativas $\left(\chi^{2}=5.78 ; p=0.016\right)$ entre las dos muestras.

El $82.3 \%$ de los primeros y el $88.1 \%$ de los segundos usaron anticoncepción en el primer coito; mientras que, un $16.5 \%$ y un $7.5 \%$, respectivamente, no lo emplearon, encontrando diferencias significativas entre los hombres de ambos cursos $\left(\chi^{2}=27.445 ; \mathrm{p}=0.000\right)$. El $92.1 \%$ de los varones del curso 97-98, y el 94.9\% de los del curso 07-08, utilizaron el preservativo; un $2.5 \%$ y un $1.0 \%$, respectivamente, el coito interrumpido, siendo poco usados los restantes métodos anticonceptivos (natural, esponja, diafragma, D.I.U. y hormonal) por los varones de ambas muestras, no encontrando diferencias significativas entre los hombres de ambos cursos $\left(\chi^{2}=\right.$ $11.60 ; \mathrm{p}=0.071)$. El $86.3 \%$ de los chicos, del curso 97 98, y el $89.7 \%$ del curso $07-08$, manifestaron no haber tenido problemas con el primer método de protección; sin embargo, un $12.6 \%$ de los primeros, y un $9.3 \%$ de los segundos, sí los tuvieron. No hallamos diferencias significativas entre ambos grupos de hombres $\left(\chi^{2}=4.03\right.$; $\mathrm{p}=0.133$.

Por último, el 76.6\% de los varones del curso 97-98, y el $80.7 \%$ del curso $07-08$, señalaron que la decisión la tomaron ellos mismos; para un $10.6 \%$ de los primeros y un $12.9 \%$ de los segundos, la propuesta fue de su pareja, y un $10.1 \%$ y un $4.2 \%$, respectivamente, la sugerencia fue de ambos. Hay diferencias significativas $\left(\chi^{2}=18.10 ; p=\right.$ $0.000)$ entre ambos grupos.

\section{Discusión}

Son el 50.6\% (97-98) y el 78.3\% (07-08) de los chicos que iniciaron sus coitos. Los resultados obtenidos ponen de manifiesto que el $90.2 \%$ de los hombres del curso 1997-98 tuvieron su primer coito con una persona de diferente sexo y el $91.9 \%$ de los hombres del curso 2007 08. El porcentaje de parejas sexuales del mismo sexo en el varón es de un $9.0 \%$ y $7.2 \%$, respectivamente. En este sentido, Doval et al. (1987), manifiestan que un $6.6 \%$ de los varones tuvieron experiencia homosexual en algún momento de su vida, siendo el porcentaje de chicos que no responden de $(7.61 \%)$, porcentaje inferior al encontrado con los varones del curso 1997-98. En el IJE2008 , la tasa entre los varones sería del $4.0 \%$, observando en la serie de los IJEs, desde el año 2000, las tasas de homosexualidad se van incrementando, pasando de un $1.6 \%$ para los varones en el año 2000 a un $3.5 \%$ para los varones en el año 2008, pero las máximas se sitúan en el año 2002, en una investigación realizada conjuntamente por la FAD y el INJUVE en la que se ensayó un procedimiento inédito para preservar la confidencialidad en la encuesta, con una tasa del 5.3\% (Comas, 2003). Por su parte, la tasa de relaciones homosexuales al menos una vez en la vida de los encuestados sobre hábitos sexuales del INE, es de un 3.9\% entre los varones de 18/49 años. Todos estos porcentajes son algo inferiores a los encontrados con los varones del curso 2007-08, debido a que ellos evalúan más la orientación del deseo sexual de la persona y no una experiencia homosexual concreta, como sucede en esta investigación en la que se trata de analizar con quien aconteció ese primer coito.

Si nos centramos en la variable relación existente con la primera pareja sexual, en ambas muestras fue con la 
novia, aunque los porcentajes decrecen significativamente del curso 1997-98 $-60.8 \%$ - al curso 2007-08 -53.7\%-; consecuentemente, se incrementó de manera significativa el porcentaje de personas que lo realizaron con una amistad o con otras personas. Diferentes estudios realizados tanto con población universitaria y como con población española y extranjera, confirman nuestros resultados. Así, los hombres en una gran proporción tienen su primera relación coital con el novio, pero un porcentaje también relevante de los mismos con la amiga.

Tomando en consideración las investigaciones desarrolladas con población española, García et al (1995), afirman que los varones universitarios navarros inician su primer relación coital, fundamentalmente, con su novia o con una amiga y un $2.2 \%$ de los mismos con una prostituta. Oraá (1996), recalca que un 64\% de ellos han mantenido su primer coito con su novia y un $24 \%$ de ellos con una amiga o desconocida.

Lasheras et al. (2005), fijan que para un 70.5\% de los varones, la novia es la opción mayoritaria para iniciar las relaciones coitales, para un $27.7 \%$ sería una amiga, y para $1.6 \%$ un profesional.

Respecto a la variable de cómo se sintieron en la primera relación coital, se pone de manifiesto que un $62.3 \%$ de los hombres del curso 1997-98 se sintieron satisfechos incrementándose este porcentaje significativamente a un $74.0 \%$ para el alumnado del curso 2007-08. Como vemos, en esta variable, acontecieron cambios significativos con el paso del tiempo. Sueiro y Diéguez (2001), afirman que el 63.8\% de los varones, se sintieron satisfechos en el primer coito, porcentajes similares a los encontrados con los varones del curso 1997-98. Otros trabajos indican que los varones en una gran proporción experimentaron sentimientos agradables o satisfactorios en su primera relación coital (Doval et al., 1987; Oraá, 1996; Repossi et al., 1993). Asimismo, Lasheras et al. (2005), reseñan que el 91\% de los hombres manifestaron sentir placer en su primer coito, el resto de los encuestados indiferencia (1.3\%), insatisfacción $(3.8 \%)$ o dolor $(0 \%)$, porcentajes éste bastante superior al encontrado con los varones del curso 2007-08.

En relación al tiempo que conocía a la persona con quién aconteció esa primera relación sexual coital, para la muestra del curso 1997-98, el porcentaje más alto es de $40.8 \%$, y para la del curso $2007-08$ de $43.3 \%$, se encuentra en el intervalo de más de 1 mes, pero menos de 1 año, encontrando cambios significativos después de 10 años. Resultados similares, con los varones del curso 1997-98, se reflejan en la investigación de Sueiro y Diéguez (2001), en donde el 30.5\% de los varones conocían a su primera pareja coital desde hacia más de un año, y el $45.7 \%$ de los varones entre 1 mes y 1 año. A su vez, López et al. (1993), anotan que el 62.5\% de los varones tienden a tener sus primeras relaciones sexuales con personas conocidas o poco conocidas.

En cuanto a la variable referida las razones por las que realizaron ese primer coito, se percibe que la que aglutina un mayor porcentaje de sujetos es el deseo, para ambas muestras -el $74.0 \%$ de la primera muestra y el $71.0 \%$ de la segunda-, seguida del amor -el $32.5 \%$ y el $27.0 \%$, respectivamente), siendo el descenso significativo en esta última. En esta línea, Repossi et al. (1993), indican que el motivo más frecuente para mantener la primera relación coital en el caso de los chicos es por cuestión de apetencia; para Lasheras et al. (2005), anotan que para un $41.6 \%$ de los hombres es por cuestión de amor, para un $23.3 \%$ por deseo, y para un $8.3 \%$ por curiosidad, porcentajes diferentes a los encontrados con los varones del curso 2007-08.

Por lo que se refiere a la variable lugar donde ocurrió la primera relación coital, se pone de manifiesto que fue la casa propia o prestada la más elegida - del $50.6 \%$ de los hombres de la primera muestra se pasa al $61.3 \%$ de la segunda-, seguido del coche $-12.8 \%$ y $8.1 \%$, respectivamente-. Los cambios acontecidos tras diez años de evolución son significativos, aumentando o disminuyendo, según los casos, no encontrando investigaciones para comparar que tengan en cuenta el lugar donde el varón realizó el primer coito.

Si analizamos la variable relativa a la frecuencia con que aconteció el coito durante el primer año, se observa que los mayores porcentajes, para ambos cursos, se encuentran en el intervalo de 1 a 3 veces al mes $-26.8 \%$ de las hombres del curso 1997-98 y disminuye a un $28.7 \%$ de las varones del curso 2007-08-, siendo significativa la diferencia con el paso del tiempo. Así, Sueiro y Diéguez (2001), reseñan que la frecuencia con que los chicos mantuvieron coito el año en que los iniciaron fueron para un $37.6 \%$ de 1 a 3 veces al mes, un $21.7 \%$ de 1 a 3 veces a la semana, un $18.3 \%$ menos de una vez al mes, y para un $12.4 \%$ sólo lo realizó la primera vez, resultados que coinciden con los encontrados con la muestra del curso 1997-98.

Si nos centramos en la variable número de parejas coitales que tuvieron durante el año en que iniciaron sus coitos, el porcentaje más elevado se observa en tener una única pareja -el 64.8\% de los hombres del curso 1997-98 $\mathrm{y}$ desciende a un 59.0\% para el curso 2007-08. Por el contrario, el número de estudiantes que tuvieron más de una pareja coital se incrementó de un $32.0 \%$, en la primera muestra, al $38.1 \%$, en la segunda. Los cambios acontecidos en esta variable, tras diez años de evolución, son significativos. En la investigación de Sueiro y Diéguez (2001), se indica que un 53.9\% tuvieron una única pareja coital durante el año en que las iniciaron, el $19 \%$ dos parejas y el $24.8 \%$ tres o más parejas, resultados inferiores a los del curso 1997-98. A su vez, Robledo et al., (2007), destacan que el $57.6 \%$ de los varones mantuvieron coitos exclusivamente con su pareja, resultado que coincide con el obtenido del curso 2007 08 .

Respecto a la variable consecución del orgasmo en el primer coito, el 82.8\% de los hombres del curso 1997-98 y el $81.5 \%$, del curso 2007-08, refirió sentirlo. Sueiro y Diéguez (2001), encuentran porcentajes similares a los del curso 1997-98 en los varones, dado que el $83.8 \%$ sintieron orgasmo en la primera relación coital.

Cuando analizamos el consumo de alcohol en el varón o por parte de su pareja antes de iniciar el primer coito o durante el mismo, el $69.3 \%$ de los varones del curso $1997-98$ y el $63.6 \%$ de los varones del curso $2007-08$, afirman que no lo consumieron; sin embargo, un $29.5 \%$ 
de los varones del curso $1997-98$ y un $34.8 \%$ del curso 2007-08 refieren consumirlo, encontrando cambios significativos después de 10 años. Sin embargo, no se han encontrado investigaciones que tengan en cuenta el consumo de alcohol por parte de la misma o de su pareja en su primer coito.

Si nos fijamos en el uso de métodos anticonceptivos por parte de los hombres en su primera relación coital, se observa un incremento en su uso por parte de los hombres del curso 2007-08 respecto a los de hace 10 años, pasando de un $82.3 \%$ a un $88.1 \%$. Los cambios acontecidos en esta variable, tras diez años de evolución, son significativos.

Centrándonos en muestras de origen español universitaria, Sueiro y Diéguez (2001), indican que un $84.8 \%$ de los chicos utilizaron algún método de protección en el primer coito, porcentaje ligeramente superior al encontrado con los varones del curso 199899. En la encuesta del INE-2002, se pone de manifiesto que en la población de edad de 18/29 años, un $78.1 \%$ de los varones afirman utilizar preservativo en su primera relación sexual, porcentaje inferior al obtenido en esta investigación, debido a que no tienen en cuenta todos los métodos anticonceptivos, haciendo referencia sólo al preservativo. Teva et al. (2009b), con muestras de diferentes Comunidades Autónomas, manifiestan que en el primer coito el $98.7 \%$ de la muestra utilizaron preservativo, frente a un $1.3 \%$ que no lo utilizaron, porcentaje este último algo inferior al del curso 2007-08.

El método más utilizado en la primera relación coital por parte de los hombres del curso 1997-98 y del curso 2007-08 es el preservativo (92.1\% y 94.9\%, respectivamente), seguido a bastante distancia por el coito interrumpido ( $2.5 \%$ y $1.0 \%$, respectivamente), los hormonales $(2.0 \%$ y $1.4 \%$, respectivamente) y los restantes apenas tienen presencia. En esta variable no se observan cambios significativos tras diez años de evolución. El uso mayoritario del preservativo en la primera relación coital, por parte de los hombres, es un dato que se reitera en todas las investigaciones, sin embargo los porcentajes de uso, cambian según el tipo de población, origen, momento de la historia en que se encuentren. Así, García et al. (1992), señalan que el preservativo es el método más utilizado por el varón en la primera relación coital; Gascón et al. (2003), señalan que el $93.2 \%$ de los varones usan el preservativo y un $6.8 \%$ de los mismos el coito interrupto, porcentajes similares al de la muestra de chicos del curso 2007-08.

Con muestras extranjeras, se observa cómo Padilla (2001), con adolescentes del Salvador, halla que el $88 \%$ utilizaron el condón como método de anticoncepción. A su vez, Cutié et al. (2005), con jóvenes cubanos, afirman que sólo un $34.1 \%$ utilizaron métodos anticonceptivos en su primer coito, de los cuales un $27.6 \%$ usaron condón, un $5.0 \%$ el coito interrupto, y $1.5 \%$ el método del ritmo. En estos dos estudios se pone de manifiesto que el uso del condón es el método más utilizado por los chicos, aunque con porcentajes más bajos que los de las muestras del curso $1997-98$ y $07-08$.

Observamos que un $86.3 \%$, de los hombres del curso 1997-98, y un 89.7\%, de los hombres del curso 2007-08, no tuvieron problemas con el uso de la primera anticoncepción, no encontrando cambios significativos después de 10 años. En la investigación de Sueiro y Diéguez (2001), se reseña que el $88.5 \%$ de los varones no tuvieron problemas con el método anticonceptivo en el primer coito, porcentajes estos similares a los encontrados con la muestra del curso 1997-98.

Respecto a quien propuso el uso de anticoncepción en el primer coito, se constata que para un $76.6 \%$, de los hombres del curso $1997-98$, y para un $80.7 \%$, de los varones del curso 2007-08, fueron ellos mismos, y sólo un $10.1 \%$ de los primeros y un $4.2 \%$ de los segundos fue una decisión consensuada por ambos, observándose cambios significativos después de 10 años de evolución. En el trabajo de Sueiro y Diéguez (2001), se resalta que el $76.9 \%$ de los varones propusieron ellos mismos el uso de la anticoncepción en la primera relación coital, porcentajes similares a los hallados con los varones del curso 1997-98.

\section{Referencias}

Comas, D., Aguinaga, J., Orazo, F., Espinosa, M.A., y Ochaita, F. (2003). Jóvenes y estilos de vida. Valores y riesgos de los jóvenes urbanos. Madrid: FAD

Doval, J.L., Perdiz, C., Seare, M. M., Sueiro, E., y Valencia, L. (1987). La sexualidad en adolescentes en Ourense. Actas III Congreso Estatal de Planificación Familiar. Valladolid, 59.

García, J.L., Avis, M., Cobos, F., Biurrum, A.C., Eslava, J.L., Rodrigo, C., Padilla, B., y Tinajas, M.R. (1995). Conductas sexuales de riesgos en universitarios-as: Un estudio en la Universidad Pública de Navarra. Cuadernos de Medicina Psicosomática y Psiquiatría de Enlace, (36), 48-60.

García, R., Fadul, R., De Moya, E.A., Gómez, E., y Herold, E. (1992). Conducta sexual del adolescente dominicano. Santo Domingo: Instituto de Sexualidad Humana.

Gascón, J.A., Navarro, B., Gascón, F.J., Férula, L.A., Jurado, A., y Montes, G. (2003). Comportamiento sexual de los escolares adolescentes en la ciudad de Córdoba. Atención Primaria, (32), 355-60.

INE (2002). Avance del censo de población de 2001. Madrid: Instituto Nacional de Estadística.

Injuve, (2008). Informe Juventud en España (2008). Madrid: Ministerio de Trabajo y Asuntos Sociales.

Injuve, (2000). Informe de la Juventud en España 2000. Madrid: Ministerio de Trabajo y Asuntos Sociales.

Lasheras, M.G., Cuñe, J., Bautista J., y Farré J.M. (2005). Hábitos sexuales en jóvenes universitarios. Cuadernos de Medicina Psicosomática y Psiquiatría de Enlace, (74), 57-63.

López, F., Lévy, J.J., Samson, J.M., Frigault, S.A., Lamer, S.A., y Lew, V. (1993). Actitudes y comportamientos sexuales frente al SIDA en un grupo de estudiantes españoles: Estudio preliminar. Cuadernos de medicina psicosomática y psiquiatría de enlace, (25), 41-51.

Oraá, R. (1996). Hábitos sexuales y conducta preventiva de los/as jóvenes de la Rioja. Cuadernos de Medicina Psicosomática y Psquiatria de Enlace, (40), 51-61.

Repossi, A., Araneda, J.M., Bustos, L., Puente, C., y Rojas, C. (1993). El estudiante universitario frente al 
sexo: ¿Qué piensa, qué sabe, qué haces? Revista Médica de Chile, (21), 201-208.

Robledo, A., López, S., Sánchez I., Del Río, L., y Barrera, E. (2007). Conocimientos y comportamientos sexuales de los adolescentes escolarizados en Parla. Sexología Integral, 4 (2), 73-79.

Rodríguez, J. y Traverso, C.I. (2007). Conductas y Educación sexual en universitarios españoles. Málaga: Grupo Editorial.
Sueiro, E. y Diéguez J.L. (2001). Juventud y sexualidad (pp. 257-269). Actas do VI Congreso GalaicoPortuguês de Psicopedagogía. Braga

Teva, I., Bermúdez, M.P., y Buela-Casal, G. (2009b). Conductas de riesgo para la infección por el VIH y las enfermedades de transmisión sexual (ETS) en adolescentes en el año 2007: diferencias en función de variables sociodemográficas. Revista Española de Salud Pública, (83), 309-320. 